Jurnal Kejaora: Jurnal Kesehatan Jasmani dan Olah Raga

ISSN: 2541-5042 (Online)

ISSN: 2503-2976 (Print)

Volume 6 Nomor 1, Edisi April 2021

\title{
PEMBELAJARAN PENDIDIKAN OLAHRAGA BERBASIS BLENDED LEARNING UNTUK SEKOLAH MENENGAH ATAS
}

\author{
Ndaru Kukuh Masgumelar ${ }^{1}$, Pinton Setya Mustafa²
}

\author{
1SMA Negeri 1 Bantur Malang \\ 2Universitas Islam Negeri Mataram \\ E-mail: ndarukukuhmasgumelar@gmail.com¹, pintonsetyamustafa@uinmataram.ac.id² \\ DOI: https://doi.org/10.36526/kejaora.v6i1.1222
}

\begin{abstract}
ABSTRAK
Pembelajaran merupakan proses transformasi pengetahuan yang melibatkan interaksi antara pebelajar dengan guru atau pebelajar dengan sumber belajar secara langsung. Teknologi yang semakin canggih membuat pembelajaran tidak hanya bertatap muka dengan guru dan guru tidak lagi menjadi satu-satunya sumber belajar melainkan dapat melalui media cetak, audio, video, audiovideo dan computer yang dikenal sebagai e-learning bahkan dapat menggunakan perangkat handphone (m-learning). Tujuan dari artikel ini adalah untuk membahas pembelajaran pendidikan olahraga berbasis blended learning dalam jenjang Sekolah Menengah Atas (SMA). Metode penelitian ini menggunakan pendekatan kepustakaan, yaitu mencari sumber referensi yang relevan untuk dikaji secara konseptual. Hasil dari pengkajian menunjukkan bahwa dengan blended learning memungkinkan pembelajaran menjadi lebih profesional untuk menangani kebutuhan belajar dengan cara yang paling efektif, efisien, dan memiliki daya tarik yang tinggi. Pemberlakuan pembelajaran berbasis blended learning pada pendidikan olahraga sangatlah membantu bagi guru pendidikan olahraga dalam penyampaian materi maupun peragaan suatu gerakan kepada peserta didik. Keuntungan yang diperoleh dengan manfaat pembelajaran berbasis blended bagi lembaga pendidikan atau pelatihan adalah memperluas jangkauan pembelajaran/pelatihan, kemudahan implementasi, efisiensi biaya, hasil yang optimal, menyesuaikan berbagai kebutuhan pebelajar, dan meningkatkan daya tarik pembelajaran.
\end{abstract}

Kata Kunci: Pembelajaran, Blended Learning, Pendidikan Olahraga

\section{PENDAHULUAN}

Perkembangan zaman dan teknologi ini tidak hanya berdampak bagi kehidupan ekonomi tetapi juga pendidikan yang ditandai dengan produk dan pemanfaatan teknologi informasi (Darmawan, 2011). Penggunaan teknologi yang tepat kepada peserta didik dapat mengeksplorasi materi yang lebih baik dengan metode pembelajaran yang bervariasi (Barlex \& Trebell, 2008; Christensen, 2014; Kavita, Sharma, \& Tiwari, 2011).

Pendidikan tidak hanya dituntut untuk dapat mengimbangi kemajuan ilmu pengetahuan dan teknologi tetapi yang terpenting sumber daya manusia juga dapat berkembang searah dengan kemajuan perkembangan tersebut. Pendidikan adalah sarana untuk mengimbangi kemajuan perkembangan ilmu pengetahuan dan teknologi dengan berbagai perubahan cara pembelajaran sesuai dengan kondisi dan tujuan pembelajaran yang akan dicapai sehingga tercipta generasi bangsa yang berkualitas dan berdaya saing tinggi.

Dahulu manusia sering mengalami kesulitan-kesulitan dikarenakan adanya beberapa keterbatasan dalam berhubungan satu dengan lainnya. Faktor-faktor yang menyebabkan terjadinya kesulitan yang dialami manusia seperti faktor jarak, waktu, jumlah, kapasitas, kecepatan, dan lain-lain. Saat ini kesulitan-kesulitan manusia dapat diatasi dengan dikembangkannya berbagai Teknologi Informasi dan Komunikasi mutakhir. Misalnya dengan adanya satelit hampir tidak ada lagi batas, jarak, dan waktu 
Jurnal Kejaora: Jurnal Kesehatan Jasmani dan Olah Raga

ISSN: 2541-5042 (Online)

ISSN: 2503-2976 (Print)

Volume 6 Nomor 1, Edisi April 2021

untuk menjangkau khalayak yang dituju di mana pun dan kapan pun.

Perencanaan pembelajaran sangat penting untuk membantu pengajar dalam mengkreasi, mengorganisasi, dan menata pembelajaran. Perencanaan pembelajaran akan berbeda bergantung pada jenis pembelajaran yang akan dilakukan (pembelajaran tatap muka atau jarak jauh), materi yang akan dipelajari oleh peserta didik, sarana dan media belajar yang tersedia, lingkungan tempat pembelajaran, dan kondisi psikologis dan interaksi peserta didik.

Pada realitanya pembelajaran belum tentu lancar sesuai dengan harapan. Tentunya masih terdapat kendala-kendala yang terjadi selama pembelajaran berlangsung yang mengakibatkan peserta didik belum tuntas capaian kompetensinya (Mustafa \& Winarno, 2020, p. 2). Kendala tersebut disebabkan oleh berbagai faktor, antara lain: materi yang sulit, fasilitas sekolah yang kurang mendukung, karakteristik peserta didik, kemampuan guru dalam mengajar, dan faktor-faktor lainnya. Untuk mengatasi kendala tersebut, maka pemanfaatan teknologi informasi dan komunikasi masa kini dalam pembelajaran sangat diperlukan. Akan tetapi dalam pembelajaran tentunya juga diimbangi dengan variasi-variasi pembelajaran yang dapat mencegah kebosanan dalam belajar, jadi porsi antara pembelajaran konvensional dan alternatif sebaiknya berimbang (Mustafa, Winarno, \& Asim, 2016, p. 173). Dalam situasi pembelajaran pendidikan olahraga banyak digunakan dibutuhkan adaptasi secara efektif dan efisien dengan maksud agar siswa lebih energik dan terampil dalam bergerak (Mustafa \& Sugiharto, 2020, p. 199; Ranti, Hermanzoni, \& Mardela, 2020, p. 1020).

Pada akhir Februari Tahun 2020 terjadi musibah besar di Indonesia yaitu pandemi Coronavirus disease-2019 (COVID19). COVID-19 adalah penyakit yang menyerang sitem pernapasan dan dapat ditularkan melalui kontak fisik dan droplet (percikan air liur) (Setiawan, 2020, p. 29). Untuk menghindari tertular COVID-19 yang mematikan diperlukan untuk mamtuhi protokol kesehatan dengan cara: memakai masker, mencuci tangan dengan sabun,

menjaga jarak dan menghindari kerumunan (Zukmadini, Karyadi, \& Kasrina, 2020, p. 68). Salah satu komponen yang sangat berdampak adalah dunia pendidikan, yaitu pembelajaran tidak dapat diterapkan seperti biasanya dengan datang ke sekolah-sekolah maupun kampus-kampus dalam perguruan tinggi. Mengingat konteks COVID-19, fokus khusus harus diberikan pada fleksibilitas pendekatan pembelajaran yang terintegrasi untuk memfasilitasi akses ke semua peserta didik untuk menghindari resiko tertular COVID-19 (Selwyn \& Jandrić, 2020, p. 1004). Guru menghadapi beberapa ketidakpastian sehubungan dengan pandemi COVID-19 saat ini, namun, temuan dari penelitian telah menunjukkan bahwa Guru Pendidikan Olahraga bersedia melakukan pengalaman jaringan internasional dan pembentukan komunitas praktik yang bermakna (O'Brien et al., 2020, pp. 518-519). Pelaksanaan blended learning sebagai pusat pendidikan menjadi pilihan alternatif yang terus meningkat secara eksponensial selama pandemi COVID-19 (Calderón, Scanlon, MacPhail, \& Moody, 2020, p. 1). Selain itu hasil review artikel yang dilakukan oleh Mujiono \& Gazali (2020, p. 60) bahwa alternatif lain dengan pemilihan pembelajaran online memberikan kemudahan dan efektivitas bagi pembelajaran pendidikan jasmani dan olahraga yang dapat memberikan pengetahuan dari jarak jauh dengan memanfaatkan platform dan aplikasi pendukung lainnya, serta pembelajaran online tetap dapat melakukan aktivitas fisik meskipun secara online.

Hasil penelitian dari Anggita, Rahayu, Ali, Castyana, \& Blume (2020, p. 699) menyatakan bahwa pandangan guru olahraga di sekolah tentang pembelajaran blended learning mudah digunakan dan dapat meningkatkan pemahaman, kreativitas, dan antusiasme siswa. Hasil review artikel dari Killian, Kinder, \& Woods (2019, p. 110) memberikan uraian bahwa pembelajran online dan blended telah muncul sebagai metode pengajaran populer di lingkungan pendidikan abad 21, dengan ciri khas asinkron dari metode tersebut mewakili potensi peningkatan kesempatan belajar dalam pendidikan jasmani. Kemudian dari 
Jurnal Kejaora: Jurnal Kesehatan Jasmani dan Olah Raga

ISSN: 2541-5042 (Online)

ISSN: 2503-2976 (Print)

Volume 6 Nomor 1, Edisi April 2021

penelitian dan pengembangan modul elektronik berbasis online yang disusun oleh Purwaningtyas \& Hariyadi (2017, p. 128) memberikan bukti bahwa melalui pembelajaran online dalam pendidikan jasmani memberikan kesempatan peserta didik untuk kreatif serta mewadahi kecepatan belajar yang berbeda-beda. Selain itu, rasa malu dapat cegah bagi peserta didik yang dalam pembelajaran konvensional ingin mengutarakan argumen secara aktif.

Dunia pendidikan Indonesia di masa mendatang lebih cenderung berkembang pada bentuk pendidikan terbuka dengan menerapkan sistem pendidikan jarak jauh (distance learning). Pembelajaranpembelajaran yang dikembangkan cenderung akan menggabungkan pembelajaran konvensional dengan pembelajaran berbasis teknologi informasi dan komunikasi (TIK). Pembelajaranpembelajaran yang menggabungkan antara pembelajaran konvensional dengan pembelajaran berbasis teknologi informasi dan komunikasi itulah yang dikembangkan sebagai pembelajaran campuran atau lebih dikenal dengan istilah blended learning, yaitu menggabungkan pem-belajaran konvensional (hanya tatap muka) dengan pembelajaran dengan memanfaatkan teknologi informasi dan komunikasi. Melalui blended learning sistem pembelajaran menjadi lebih luwes dan tidak kaku.

Berdasarkan latar belakang yang telah diuraikan, maka akan dibahas tentang karakteristik pembelajaran pendidikan olahraga menggunakan pendekatan blended learning pada jenjang SMA. Tujuan dari artikel ini adalah memberikan informasi dan kajian kepustakaan mengenai blended learning apabila diterapkan dalam pendidikan olahraga. Berbeda pada pelajaran umum, karena pendidikan olahraga memiliki ciri khas, yaitu melalui aktivitas fisik dijadikan alternatif untuk mendidik siswa di sekolah.

\section{METODE}

Penelitian ini merupakan tinjauan kepustakaan, yaitu mencari sumber referensi yang relevan dari: buku, jurnal, dan artikel tentang "blended learning pada pendidikan olahraga di tingkat SMA secara nasional"

kemudian dikaji dan dibahas. Pengumpulan data menggunakan pencarian melalui buku berupa media cetak dan penelusuran online di google scholar dengan kata kunci: ("pendidikan olahraga" OR "pendidikan jasmani" OR PJOK) AND "blended learning" AND ("SMA" OR "SMK" OR "Sekolah Menengah Atas" OR "Sekolah Menengah Kejuruan") dengan rentang pencarian Tahun 2010 sampai dengan referensi yang terbit bulan Februari Tahun 2021, namun tidak menutup kemungkinan jika diperlukan rujukan sebelum Tahun 2010. Selain itu juga didukung dengan sumber primer dari buku tentang pendidikan dan pembelajaran. Dikarenakan penelitian ini adalah jenis penelitian kualitatif, maka instrumen penelitian adalah peneliti sendiri yang menelusuri data dari referensi yang relevan untuk disajikan dalam penelitian ini. Analisis data menggunaan pendekatan kualitatif yaitu hasil uraian dari para ahli dan penelitian dianalisis untuk diungkapkan kembali menjadi narasi dengan tahapan: reduksi data, penyajian data, dan menyimpulkan (Sugiyono, 2015, p. 337). Reduksi data dilakukan dari hasil temuan pernyataan para ahli dan penelitian yang dipublikasikan melalui artikel. Kemudian diuraikan dengan kalimat singkat. Pada akhirnya diperoleh kesimpulan berupa kajian konseptual pembelajaran pendidikan olahraga berbasis blended learning pada jenjang SMA.

\section{HASIL DAN PEMBAHASAN Konsep Blended Learnig}

Istilah blended learning secara ketatabahasaan terdiri dari dua kata yaitu Blended dan Learning. Kata Blend berarti "campuran bersama untuk meningkatkan kualitas agar bertambah baik" (Collins Dictionary), atau formula suatu penyelarasan kombinasi atau perpaduan (Heinze \& Procter, 2006, p. 236), sedangkan learning memiliki makna umum yakni belajar, dengan demikian sepintas mengandung makna pola pembelajaran yang mengandung unsur pencampuran, atau penggabungan antara satu pola dengan pola yang lainnya.

Hasil penelitian yang dilakukan Dziuban \& Moskal (2011, p. 24) menemukan bahwa program blended learning memiliki 
Jurnal Kejaora: Jurnal Kesehatan Jasmani dan Olah Raga

ISSN: 2541-5042 (Online)

ISSN: 2503-2976 (Print)

Volume 6 Nomor 1, Edisi April 2021

potensi untuk meningkatkan hasil belajar mahasiswa dan juga menurunkan tingkat putus sekolah dibandingkan dengan pembelajaran yang sepenuhnya pembelajaran online. Demikian juga ditemukan bahwa model pembelajaran berbasis blended lebih baik daripada pembelajaran tatap muka (face to face). Hakikatnya pembelajaran adalah proses mengubah perilaku (kognitif, afektif, psikomotor) yang relatif permanen sebagai hasil dari latihan dan pengalaman (Mustafa, 2021, p. 56). Pebelajar dan pengajar/fasilitator bekerja sama untuk meningkatkan kualitas pembelajaran. Tujuan utama pembelajaran blended adalah memberikan kesempatan bagi berbagai karakteristik pebelajar agar terjadi belajar mandiri, berkelanjutan, dan berkembang sepanjang hayat, sehingga belajar akan menjadi lebih efektif, lebih efisien, dan lebih menarik (Christensen, 2014; Prasetyo, 2020, p. 11).

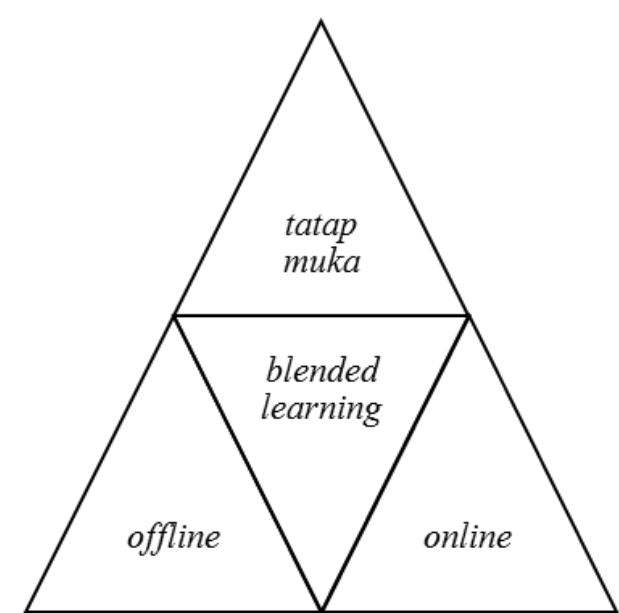

Gambar 1. Komponen Pembelajaran

Berbasis Blended Learning (PBBL)

(Sumber: Dwiyogo, 2016, p. 46)

Pembelajaran dalam konsep blended learning terbagi menjadi tiga jenis pembelajaran, yaitu: tatap muka, offline, dan online. Pembelajaran tatap muka sebagai salah satu bentuk model pembelajaran konvensional yang mempertemukan pendidik (guru atau dosen) dengan murid dalam satu ruangan untuk belajar. Pembelajaran tatap muka merupakan seperangkat tindakan yang dirancang untuk mendukung proses belajar peserta didik secara langsung. Model pembelajaran tatap muka lebih menekankan pada pengenalan serta demonstrasi pembelajaran dan mengharuskan pelakunya untuk terus bertemu dan berinteraksi dalam konteks pembelajaran setiap minggu (Neuhauser, 2002, p. 103; Ni, 2013, p. 201; Widiyanti, Julyasih, \& Santiasa, 2020, p. 148). Pembelajaran tatap muka lebih menekankan kepada aktivitas peserta didik (Khine \& Lourdusamy, 2003, p. 675). Dengan pembelajaran tatap muka kendala-kendala dari siswa dapat diketahui oleh guru.

Pembelajaran offline sering diidentikkan dengan pembelajaran menggunakan media berbasis komputer tanpa jaringan internet. Salah satu model pembelajaran offline adalah penggunaan multimedia. Neo \& Neo (2002, p. 80) perubahan dalam proses belajar mengajar tidak bisa dihindari dengan pengenalan multimedia teknologi di bidang pendidikan. Abdous \& Yen (2010, p. 256) menjelaskan siswa dianjurkan diberi banyak cara untuk memperoleh ilmu diantaranya dengan cara memaksimalkan komputer.

Menurut Dwiyogo (2008, p. 92) komponen-komponen dalam multimedia adalah: (1) harus ada komputer yang mengkoordinasikan apa yang dilihat dan didengar, yang berinteraksi dengan kita, (2) harus ada link yang menghubungkan kita dengan informasi, (3) harus ada alat navigasi yang memandu kita, menjelajah jaringan informasi yang saling terhubung, (4) multimedia menyediakan tempat kepada kita untuk mengumpulkan, memproses dan mengkomunikasikan informasi dan ide kita sendiri.

Belajar online merupakan hasil dari pengajaran yang disampaikan secara elektronik menggunakan media berbasis komputer dan seringkali diakses melalui sebuah jaringan internet yang membantu pebelajar untuk mencapai hasil yang spesifik (Bawaneh, 2011, p. 68; McGreal \& Elliott, 2004, p. 115). Dengan pembelajaran online proses belajar mengajar terus secara menyebar diarahkan ke arah yang lebih fleksibel terhadap waktu dan tempat (Ginns \& Ellis, 2007, p. 56; Wiarto, 2016, p. 159). Kegiatan belajar mengajar yang dilakukan 
Jurnal Kejaora: Jurnal Kesehatan Jasmani dan Olah Raga

ISSN: 2541-5042 (Online)

ISSN: 2503-2976 (Print)

Volume 6 Nomor 1, Edisi April 2021

secara online dikombinasikan dengan tatap muka maka akan mempengaruhi nilai akhir siswa (Dziuban \& Moskal, 2011, p. 238). Sutopo (2012, p. 143) menjelaskan empat hal yang menjadi implikasi dalam pembelajaran online, yaitu: (1) siswa harus menentukan secara eksplisit apa yang harus dihasilkan sehingga dia dapat menentukan pilihan apa yang akan dipelajari, (2) siswa harus dapat mengevaluasi dirinya sendiri apakah berhasil atau tidak dalam pembelajaran online, (3) bahan ajar harus mempunyai tahapan yang memadai untuk menunjang pembelajaran, tahapan dari yang sederhana ke kompleks, mudah dan sulit, (4) siswa harus dilengkapi dengan umpan balik sehingga dia dapat

memantau apa yang telah dikerjakan dan memperbaiki kesalahannya.

Merujuk pada definisi blended learning oleh Chaeruman (2011:4) yaitu pembelajaran yang mengkombinasikan setting pembelajaran synchronous dan asynchronous secara tepat guna untuk mencapai tujuan pembelajaran, maka karakteristik model blended learning dengan pendekatan konstruktif (constructive approach) ini memiliki dua setting pembelajaran, yaitu pembelajaran synchronous dan asynchronous. Adapun karakteristik blended learning ini digambarkan dalam bagan berikut:

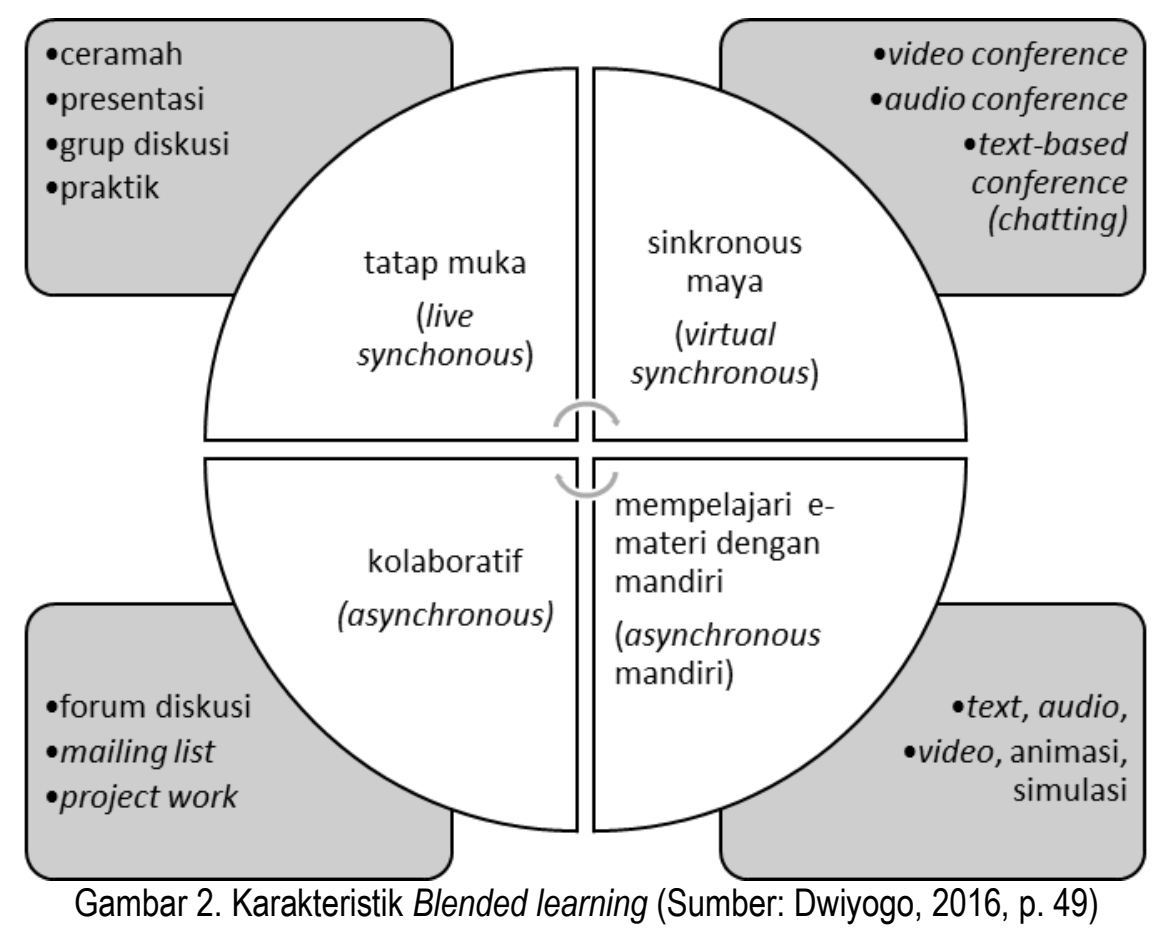

Kelebihan blended learning: (a) pembelajaran terjadi secara mandiri dan konvensional, yang keduanya memiliki kelebihan yang dapat saling melengkapi, (b) pembelajaran lebih efektif dan efisien, (c) peningkatan aksesbilitas. Dengan adanya Blended learning maka peserta belajar semakin mudah dalam mengakses materi pembelajaran.

Kekurangan Blended learning: (a) media yang dibutuhkan sangat beragam, sehingga sulit diterapkan apabila sarana dan pra-sarana tidak mendukung, (b) tidak meratanya fasilitas yang dimiliki pelajar, seperti komputer dan akses internet. Padahal dalam Blended learning diperlukan akses internet yang memadai, apabila jaringan kurang memadai akan menyulitkan peserta dalam mengikuti pembelajaran mandiri via online, (c) kurangnya pengetahuan masyarakat terhadap penggunaan teknologi, (d) tidak meratanya fasilitas yang dimiliki pelajar, seperti komputer dan akses internet. 
Jurnal Kejaora: Jurnal Kesehatan Jasmani dan Olah Raga

ISSN: 2541-5042 (Online)

ISSN: 2503-2976 (Print)

Volume 6 Nomor 1, Edisi April 2021

\section{Pendidikan Olahraga}

Pendidikan olahraga merupakan olahraga pendidikan yang diajarkan melalui sekolah mulai dari jenjang pendidikan dasar hingga pendidikan menengah, biasanya mata pelajarannya berupa pendidikan jasmani, olahraga, dan kesehatan (PJOK). PJOK adalah bagian dari pendidikan dengan ciri khas membelajarkan siswa melalui aktivitas gerak jasmani untuk mencapai tujuan kompetensi (Mustafa \& Roesdiyanto, 2021, p. 62). Tujuan pendidikan olahraga adalah mendidik siswa menjadi individu yang seutuhnya dan membantu mereka berkembang sebagai jiwa yang terampil yang kompeten, melek literasi, dan aktif dalam hidup (Siedentop, Hastie, \& Mars, 2011, p. 4). Di satu sisi, pendidikan olahraga merupakan pengalaman belajar kooperatif yang terpenting bagi siswa, mereka belajar bekerja sama satu sama lain untuk mencapai tujuan kelompok (Rink, 2014, p. 285). Aktivitas fisik membuat badan menjadi bugar, sehingga dengan kondisi kebugaran yang baik dapat memaksimalkan kemampuan siswa dalam belajar (Adi, Supriyadi, \& Masgumelar, 2020, p. 39). Oleh karena itu peran guru dalam pendidikan olahraga berbeda dengan pengajaran biasa.

Pendidikan olahraga diusulkan sebagai model pembelajaran yang menangani masalah pendekatan tradisional untuk mengajar pendidikan jasmani (Romar, Henriksson, Ketomäki, \& Hastie, 2016, p. 1). Dalam pendidikan olahraga yang tidak boleh dilupakan adalah pengembangan keterampilan motorik, pengetahuan taktis dan kinerja, kebugaran, pengembangan pribadi dan sosial, serta sikap dan nilai siswa (Alexander \& Luckman, 2001, p. 243). Alokasi waktu yang digunakan dalam materi PJOK adalah $3 \times 45$ menit, dengan rincian PJOK dibagi menjadi $2 \times 45$ menit untuk praktik lapangan, dan 1 x 45 menit dilaksanakan dengan pembelajaran di kelas, karena aspek kognitif perlu mendapat perhatian untuk membantu membentuk materi (teoretis) pengetahuan (Purwaningtyas \& Hariyadi, 2017, p. 122). Selain itu, salah satu alternatif yaitu guru perlu menggunakan media video sebagai sumber pembelajaran untuk meningkatkan motivasi belajar siswa dan

meningkatkan kemampuan belajar PJOK (Carolin, Astra, \& Suwiwa, 2020, p. 17). Guru PJOK merupakan salah satu agen terpenting dalam memberikan bimbingan dan layanan bagi peserta didik dalam memperoleh pertumbuhan dan perkembangan psikis sekaligus fisik secara maksimal (Mustafa, 2020 , p. 61). Oleh karena itu rancangan blended learning yang diadopsi hendaknya menstimulus siswa untuk aktif dalam bergerak dan berolahraga. Jangan sampai dengan kemudahan akses sumber belajar menjadikan siswa lebih aktif secara kognitif daripada motorik. Sebab, esensi dari pendidikan olahraga adalah aktif bergerak untuk kesehatan dan kesejahteraan hidup.

\section{Blended Learning Pendidikan Olahraga pada Sekolah Menengah Atas}

Istilah blended learning pada awalnya digunakan untuk menggambarkan mata kuliah yang mencoba menggabungkan pembelajaran tatap muka dengan pembelajaran online. Saat ini istilah blended menjadi populer, maka semakin banyak kombinasi yang dirujuk sebagai blended learning. Dalam metodologi penelitian, digunakan istilah mixing untuk menunjukkan kombinasi antara penelitian kuantitatif dan kualitatif. Adapula yang menyebut di dalam pembelajaran adalah pendekatan eklektif, yaitu mengkombinasi berbagai pendekatan dalam pembelajaran. Namun, pengertian pembelajaran berbasis blended learning adalah pembelajaran yang mengkombinasi strategi penyampaikan pembelajaran menggunakan kegiatan tatap muka, pembelajaran berbasis komputer (offline), dan komputer secara online (internet dan mobile learning). Bagaimana penerapan blended learning di SMA?

Penerapan blended learning pada bidang studi pendidikan olahraga di SMA akan menambah model pembelajaran yang selama ini hanya menggunakan tatap muka dalam belajar. Kegiatan diharapkan lebih interakif antara guru dan peserta didik maupun dengan sesama peserta didik. Blended learning merupakan alat bantu belajar bagi siswa yang kebutuhan akan belajarnya masih di bawah rata-rata. Dengan sifatnya yang membuat pembelajaran lebih 
Jurnal Kejaora: Jurnal Kesehatan Jasmani dan Olah Raga

ISSN: 2541-5042 (Online)

ISSN: 2503-2976 (Print)

Volume 6 Nomor 1, Edisi April 2021

menarik maka blended learning ini mampu menarik perhatian siswa untuk mengikuti kegiatan olahraga.

Karakteristik perkembangan intelektual remaja digambarkan oleh Keating (Yusuf, 2004, pp. 195-196) sebagai berikut: (1) kemampuan intelektual remaja telah sampai pada fase operasi formal sebagaimana konsep Piaget. Berlainan dengan cara berpikir anak-anak yang tekanannya kepada kesadaran sendiri di sini dan sekarang (here and now), cara berpikir remaja berkaiatan erat dengan dunia kemungkinan (world of possibilities), (2) melalui kemampuannya untuk menguji hipotesis, muncul kemampuan nalar secara ilmiah, (3) mampu memikirkan masa depan dan membuat perencanaan dan mengeksplorasi berbagai kemungkinan untuk mencapainya, (4) mampu menyadari aktivitas kognitifnya dan mekanisme yang membuat proses kognitif tersebut efisien atau tidak efisien, (5) cakrawala berpikirnya semakin luas.

Pelaksanaan pembelajaran dapat dirancang dengan mengkominasikan media belajar karena gaya belajar tiap siswa berbeda. Kita sebagai seorang pendidik atau orang tua tidak bisa memaksakan seorang siswa harus belajar dengan suasana dan cara yang kita inginkan karena masing-masing siswa atau individu memiliki tipe atau gaya belajar sendiri-sendiri. Salah satu hal yang dapat dilakukan dengan blended learning adalah kombinasi pembelajaran jarak jauh dan penggunaan multimedia interaktif atau media audio visual untuk mencapai pembelajaran offline (Dwiyogo \& Cholifah, 2016, p. 953).

Gaya belajar merupakan cara tercepat dan terbaik bagi setiap individu untuk bisa menyerap sebuah informasi dari luar dirinya (Uno, 2006, p. 180). Pendapat lain dari Sukirno (2010, p. 27) karakteristik belajar siswa dapat dikelompokkan menjadi tiga macam, yaitu karakteristik gaya belajar visual, gaya auditorial, dan gaya kinestetik. Gaya belajar visual (visual learners) menitik beratkan pada ketajaman penglihatan dengan ciri-ciri diantaranya sebagai berikut: (1) rapi dan teratur, (2) berbicara dengan cermat, (3) perencana dan pengatur jangka

panjang yang baik, (4) teliti terhadap detail, (5) mementingkan penampilan baik dalam hal pakaian maupun presentasi, (6) pengeja yang baik dan melihat kata yang sebenarnya dalam pikiran mereka, (7) mengingat apa yang dilihat, daripada yang didengar, (8) mengingat dengan asosiasi visual, (9) biasanya tidak terganggu oleh keributan, (10) mempunyai masalah untuk mengingat intruksi verbal kecuali jika ditulis dan sering kali meminta bantuan orang untuk mengulanginya, (11) pembaca cepat dan tekun, (12) lebih suka membaca daripada dibacakan, (13) membutuhkan pandangan dan tujuan yang menyeluruh dan bersikap waspada sebelum secara mental merasa pasti tentang sesuatu masalah atau proyek, (14) mencoret-coret tanpa arti selama berbicara di telepon dan dalam rapat, (15) lupa menyampaikan pesan verbal kepada orang lain.

Gaya belajar auditori (auditory learners) mengandalkan pada pendengaran untuk bisa memahami dan mengingatnya dengan ciri- ciri sebagai berikut: (1) berbicara pada diri sendiri saat bekerja, (2) mudah terganggu oleh keributan, (3) menggerakkan bibir dan mengucapkan tulisan di buku ketika membaca, (4) senang membaca dengan keras dan mendengarkan, (5) dapat mengulangi kembali dan menirukan nada, irama, dan warna suara, (6) merasa kesulitan untuk menulis, tetapi hebat dalam bercerita, (7) berbicara dalam irama yang terpola, (8) biasanya pembicara yang fasih, (9) lebih suka musik daripada seni, (10) belajar mendengarkan dan mengingat yang didiskusikan daripada yang dilihat, (11) senang berbicara, senang berdiskusi, dan menjelaskan sesuatu panjang lebar, (12) mempunyai masalah dengan pekerjaanpekerjaan yang melibatkan visualisasi, (13) lebih pandai mengeja dengan keras daripada melukiskannya, (14) lebih senang gurauan lisan daripada membaca komik, (15) suka bertanya kepada masalah yang kurang jelas ketika mendengar.

Gaya belajar kinestetik (kinesthetic learners) meng-haruskan individu yang bersangkutan menyentuh sesuatu yang memberikan informasi tertentu agar ia bisa mengingatnya dengan ciri-ciri sebagai 
Jurnal Kejaora: Jurnal Kesehatan Jasmani dan Olah Raga

ISSN: 2541-5042 (Online)

ISSN: 2503-2976 (Print)

Volume 6 Nomor 1, Edisi April 2021

berikut: (1) berbicara dengan perlahan, (2) menanggapi perhatian fisik, (3) menyentuh orang untuk mendapatkan perhatian mereka, (4) berdiri dekat ketika berbicara dengan seseorang, (5) selalu berorientasi pada fisik dan banyak bergerak, (6) mempunyai perkembangan awal otot-otot yang besar, (7) belajar melalui memanipulasi dan praktik, (8) menghafal dengan cara berjalan dan melihat, (9) menggunakan jari sebagai penunjuk ketika membaca, (10) banyak menggunakan isyarat tubuh, (11) tidak dapat duduk diam untuk waktu lama, (12) tidak dapat mengingat geografi, kecuali mereka pernah berada di tempat itu, (13) menggunakan kata-kata yang mengandung aksi, (14) menyukai buku-buku yang berorientasi pada plot-mereka mencerminkan aksi dengan gerakan tubuh saat membaca, (15) kemung-kinan tulisannya jelek, (16) ingin melakukan segala sesuatu, (17) menyukai permainan yang menyibukkan.

Pengembangan langkah-langkah pembelajaran dalam blended learning. Pada pengembangan pembelajaran baik dengan menerapkan Blended learning maupun secara konvensional, pendidik perlu mengembangkan langkah-langkah pembelajaran yang tepat dalam suatu rencana pelaksanaan pembelajaran (RPP) berdasarkan kompetensi dasar-kompetensi dasar yang ingin dicapai dalam pembelajaran. Pengembangan langkahlangkah pembelajaran yang menerapkan Blended learning juga perlu dirancang dengan baik, sehingga dalam pelaksanaan pembelajarannya peserta didik tidak merasa kesulitan secara teknis. Oleh karena itu, pendidik perlu mempersiapkan terlebih dulu segala hal yg dibutuhkan, seperti materimateri yang akan disampaikan atau dibahas, platform yang akan digunakan dalam pembelajaran dengan Blended learning, tutorial penggunaan platform yang digunakan dalam pembelajaran dengan menerapkan Blended learning dan lain sebagainya.

Sebelum melaksanakan pembelajaran dengan menerapkan blended learning, pendidik harus menyiapkan dulu semua kebutuhan pembelajarannya terutama penggunaan platform teknologi yang akan digunakan dalam pembelajaran yang akan

digunakan tanpa melak-sanakan tatap muka. Beberapa platform yang dapat digunakan dalam pembelajaran dengan blended learning seperti Group Mailing List (Milis, seperti Yahoo groups, Google+, dan lainlain), Web Blog Guru, Social Media (Facebook, Twitter, Instagram, Path, dan lainlain), Aplikasi-aplikasi Learning Management Systems atau LMS (seperti Moodle, Edmodo, Quipper, Kelase, dan lainnya) dan sebagainya. Selanjutnya, bagaimana platform-platform yang sudah ditentukan oleh pendidik diterapkan dalam pembelajaran dengan sebelumnya disusun terlebih dahulu dalam langkah-langkah pembelajaran yang dirancang. Sehingga dapat dikatakan sebelum merancang PBBL guru perlu melakukan analisis kebutuhan dan potensi yang dapat dimanfaatkan dalam lingkungan belajar (Masgumelar \& Dwiyogo, 2020, p. 96). Dalam era abad 21 ini pembelajaran pendidikan olahraga dituntut untuk memanfaatkan device untuk dibuatkan isi materi pelajaran dari guru, jadi tidak hanya melakukan aktivitas fisik saja namun perlu memberdayakan teknologi masa kini sebagai sumber belajar (Mustafa \& Dwiyogo, 2020, p. 422).

Hasil penelitian dari Masgumelar, Dwiyogo, \& Nurrochmah (2019, p. 985) menunjukkan bahwa pembelajaran PJOK di jenjang SMA dapat dikemas melalui blended learning, karena dapat mempermudah peserta didik dalam mengakses materi PJOK dengan mudah, sehingga pembelajaran menjadi efektif dan efisien. Blended learning dalam pendidikan olahraga dapat dibagi menjadi tiga aspek, antara lain: (1) face to face, yaitu pembelajaran yang menghadirkan guru dan peserta didik untuk bertemu dalam satu tempat yaitu pada sekolah; (2) offline, melalui sumber belajar multimedia interaktif yang dibuat oleh guru yaitu terdiri dari teks, video, audio, dan animasi serta dapat diakses tanpa jaringan internet; dan (3) online, yaitu dengan penyedia web belajar online, dapat melalui google classroom atau edmodo atau penyedia jasa web pembelajaran lainnya. Melalui pembelajaran online ini, memungkinkan peserta didik untuk mengakses dengan bebas sumber belajar yang diunggah oleh guru dalam kelas online 
Jurnal Kejaora: Jurnal Kesehatan Jasmani dan Olah Raga

ISSN: 2541-5042 (Online)

ISSN: 2503-2976 (Print)

Volume 6 Nomor 1, Edisi April 2021

yang tentunya membutuhkan jaringan internet. Tiga komponen tersebut saling melengkapi, sesuai dengan kebutuhan di lapangan, tentunya guru perlu merancang bagaimana agar porsi tatap muka, offline, dan online tersebut efektif dan efisien.

\section{KESIMPULAN}

Blended learning merupakan proses pembelajaran yang memanfaatkan berbagai macam pendekatan. Pendekatan yang dilakukan dapat memanfaatkan berbagai macam media dan teknologi. Pembelajaran berlangsung secara konvensional (tatap muka), mandiri, dan mandiri via online. Bahan belajar mandiri secara offline disiapkan dalam bentuk digital, seperti dalam bentuk CD, MP3, DVD, dan sejenisnya, sedangkan bahan belajar mandiri secara online disiapkan dalam bentuk Mailing List, Social Media, Learning Management Systems (LMS) dan lain sebagainya. Pelaksanaan pembelajaran dengan Blended learning secara online dapat diterapkan dalam beberapa model yaitu web course, web centric course, dan web enhanced course. Pada implemetasinya, pembelajaran dengan blended learning pada lembaga pendidikan dasar dan menengah lebih tepat dengan menerapkan model web centric course, dan web enhanced course, karena pada pendidikan dasar dan menengah masih diwajibkan adanya tatap muka di dalam kelas.

Pada penerapan Blended learning pendidik seharusnya dapat memastikan bahwa seluruh pesertanya memiliki sarana dan prasarana yang memadai, sehingga dalam belajar secara mandiri via online tidak banyak hambatan dikarenakan faktor sarana dan prasana yang kurang memadai. Selain itu pendidik sudah menyiapkan solusi terbaik dalam mengatasi permasalahan yang mungkin muncul. Pembagian materi belajar harus dapat dialokasikan dengan baik, dengan mempertimbangkan isi bahan ajar, serta tujuan pembelajarannya, mana yang harus dibahas secara tatap muka, atau dapat dipelajari secara mandiri. Dalam mengorganisir pembelajaran, pendidik juga harus menyiapkan jadwal yang terorganisir untuk tatap muka dan pembelajaran mandiri

diawal, agar peserta mengetahui secara jelas jadwal tersebut.

\section{DAFTAR PUSTAKA}

Abdous, M., \& Yen, C.-J. (2010). A predictive study of learner satisfaction and outcomes in face-to-face, satellite broadcast, and live video-streaming learning environments. The Internet and Higher Education, 13(4), 248257.

https://doi.org/10.1016/j.iheduc.2010. 04.005

Adi, S., Supriyadi, \& Masgumelar, N. K. (2020). Model-Model Exercise dan Aktivitas Fisik untuk Kebugaran Jasmani Anak SD. Malang: Wineka Media.

Alexander, K., \& Luckman, J. (2001). Australian Teachers Perceptions and Uses of the Sport Education Curriculum Model. European Physical Education Review, 7(3), 243-267. https://doi.org/10.1177/1356336X010 073002

Anggita, G. M., Rahayu, T., Ali, M. A., Castyana, B., \& Blume, A. (2020). Tingkat pengetahuan dan persepsi guru penjas terhadap metode blended learning. Jurnal SPORTIF: Jurnal Penelitian Pembelajaran, 6(3), 699712.

https://doi.org/https://doi.org/10.29407 /js_unpgri.v7i1.14815

Barlex, D. M., \& Trebell, D. (2008). Designwithout-make: challenging the conventional approach to teaching and learning in a design and technology classroom. International Journal of Technology and Design Education, 18(2), 119-138. https://doi.org/10.1007/s10798-0079025-5

Bawaneh, S. S. (2011). The effects of blended learning approach on students' performance: Evidence from a computerized accounting course. International Journal of Humanities and Social Science, 1(6), 63-69.

Calderón, A., Scanlon, D., MacPhail, A., \& Moody, B. (2020). An integrated blended learning approach for 
Jurnal Kejaora: Jurnal Kesehatan Jasmani dan Olah Raga

ISSN: 2541-5042 (Online)

ISSN: 2503-2976 (Print)

Volume 6 Nomor 1, Edisi April 2021

physical education teacher education programmes: teacher educators' and pre-service teachers' experiences. Physical Education and Sport Pedagogy, 1-16. https://doi.org/10.1080/17408989.202 0.1823961

Carolin, L. L., Astra, I. K. B., \& Suwiwa, G. (2020). Pengembangan Media Video Pembelajaran Dengan Model Addie Pada Materi Teknik Dasar Tendangan Pencak Silat Kelas VII SMP Negeri 4 Sukasada Tahun Pelajaran 2019/2020. Jurnal Kejaora (Kesehatan Jasmani Dan Olah Raga), 5(2), $\quad$ 12-18. https://doi.org/10.36526/kejaora.v5i2. 934

Chaeruman, U. A. (2011). Implementing Blended Learning: A Case Based Sharing Experience.

Christensen, R. (2014). Effect of Technology Integration Education on the Attitudes of Teacher and Students. Journal of Research on Technology in Education, 34(4), 411-433.

Darmawan, D. (2011). Teknologi Pembelajaran. Bandung: PT Remaja Rosdakarya.

Dwiyogo, W. D. (2008). Aplikasi Teknologi Pembelajaran: Pengembangan Media Pembelajaran Pendidikan Jasmani dan Olahraga. Malang: FIP UM.

Dwiyogo, W. D. (2016). Pembelajaran Berbasis Blended learning: Model Rancangan Pembelajaran dan Hasil Belajar Pemecahan Masalah. Malang: Wineka Media.

Dwiyogo, W. D., \& Cholifah, P. S. (2016). Continuing Professional Development (CPD) for Physical Education Teacher in Elementary School through Blended Learning. International Conference on Education (ICE2) 2018: Education and Innovation in Science in the Digital Era, 948-955. Malang: Universitas Negeri Malang.

Dziuban, C., \& Moskal, P. (2011). A course is a course is a course: Factor invariance in student evaluation of online, blended and face-to-face learning environments. The Internet and Higher

Education, 14(4), 236-241. https://doi.org/10.1016/j.iheduc.2011. 05.003

Ginns, P., \& Ellis, R. (2007). Quality in blended learning: Exploring the relationships between on-line and face-to-face teaching and learning. The Internet and Higher Education, 10(1), 53-64. https://doi.org/10.1016/j.iheduc.2006. 10.003

Heinze, A., \& Procter, C. (2006). Online Communication and Information Technology Education. Journal of Information Technology Education: Research, 5(1), 235-249.

Kavita, V., Sharma, J. P., \& Tiwari, R. K. (2011). Use of Information Technology in Physical Education and Sport. International Journal in Multidisciplinary and Academic Research, 2(4), 1-6.

Khine, M. S., \& Lourdusamy, A. (2003). Blended learning approach in teacher education: combining face-to-face instruction, multimedia viewing and online discussion. British Journal of Educational Technology, 34(5), 671675. https://doi.org/10.1046/j.00071013.2003.00360.x

Killian, C. M., Kinder, C. J., \& Woods, A. M. (2019). Online and Blended Instruction in K-12 Physical Education: A Scoping Review. Kinesiology Review, 8(2), 110-129. https://doi.org/10.1123/kr.2019-0003

Masgumelar, N. K., \& Dwiyogo, W. D. (2020). Development of Game Modification Using Blended Learning in Physical Education, Sports, and Health For Senior High School Students. The 3rd International Conference on Sports Sciences and Health 2019 (ICSSH 2019), 95-100. Atlantis Press.

Masgumelar, N. K., Dwiyogo, W. D., \& Nurrochmah, S. (2019). Modifikasi Permainan menggunakan Blended Learning Mata Pelajaran Pendidikan Jasmani, Olahraga, dan Kesehatan. Jurnal Pendidikan: Teori, Penelitian, Dan Pengembagan, 4(7), 979-986. 
Jurnal Kejaora: Jurnal Kesehatan Jasmani dan Olah Raga

ISSN: 2541-5042 (Online)

ISSN: 2503-2976 (Print)

Volume 6 Nomor 1, Edisi April 2021

McGreal, R., \& Elliott, M. (2004). Technologies of Online Learning (eLearning). In T. Anderson \& F. Elloumi (Eds.), Theory and Practice of Learning (pp. 115-135). Athabasca, Kanada: Athabasca University.

Mujiono, M., \& Gazali, N. (2020). Literature review: Physical education in the covid-19 pandemic. JUARA: Jurnal Olahraga, 6(1), 50-63. https://doi.org/10.33222/juara.v6i1.10 54

Mustafa, P. S. (2020). Implikasi Pola Kerja Telensefalon dan Korteks Cerebral dalam Pendidikan Jasmani. Media IImu Keolahragaan Indonesia, 10(2), 53-62.

https://doi.org/https://doi.org/10.15294 /miki.v10i2.24901

Mustafa, P. S. (2021). Implementation of Behaviorism Theory-based Training Learning Model in Physical Education in Class VII Junior High School Football Game Materials. COMPETITOR: Jurnal Pendidikan Kepelatihan Olahraga, 13(1), 39-60. https://doi.org/https://doi.org/10.26858 /cjpko.v13i1.18131

Mustafa, P. S., \& Dwiyogo, W. D. (2020). Kurikulum Pendidikan Jasmani, Olahraga, dan Kesehatan di Indonesia Abad 21. JARTIKA Jurnal Riset Teknologi Dan Inovasi Pendidikan, 3(2), $\quad$ 422-438. https://doi.org/10.36765/jartika.v3i2.2 68

Mustafa, P. S., \& Roesdiyanto, R. (2021). Penerapan Teori Belajar Konstruktivisme melalui Model PAKEM dalam Permainan Bolavoli pada Sekolah Menengah Pertama. Jendela Olahraga, 6(1), 50-65. https://doi.org/10.26877/jo.v6i1.6255

Mustafa, P. S., \& Sugiharto, S. (2020). Keterampilan Motorik pada Pendidikan Jasmani Meningkatkan Pembelajaran Gerak Seumur Hidup. Sporta Saintika, 5(2), 199-218. https://doi.org/10.24036/sporta.v5i2.1 33

Mustafa, P. S., \& Winarno, M. E. (2020). Pengembangan Buku Ajar Pengajaran 
Jurnal Kejaora: Jurnal Kesehatan Jasmani dan Olah Raga

ISSN: 2541-5042 (Online)

ISSN: 2503-2976 (Print)

Volume 6 Nomor 1, Edisi April 2021

Elektronik Berbasis Online dengan Program Edmodo. Jurnal Pendidikan, 2(1), 123, 121-129.

Ranti, S., Hermanzoni, H., \& Mardela, R. (2020). Pelaksanaan Pembelajaran Pendidikan Jasmani Olahraga dan Kesehatan. Jurnal Patriot, 2(4), 10191035.

Rink, J. E. (2014). Teaching Physical Education for Learning (7, Ed.). New York: McGraw-Hill Companies.

Romar, J.-E., Henriksson, J., Ketomäki, K., \& Hastie, P. (2016). Teachers' Learning Experiences with the Sport Education Model in Physical Education. Scandinavian Sport Studies Forum, 7 , 1-26.

Selwyn, N., \& Jandrić, P. (2020). Postdigital Living in the Age of Covid-19: Unsettling What We See as Possible. Postdigital Science and Education, 2(3), $\quad$ 989-1005. https://doi.org/10.1007/s42438-02000166-9

Setiawan, A. R. (2020). Lembar Kegiatan Literasi Saintifik untuk Pembelajaran Jarak JauhTopik Penyakit Coronavirus 2019 (COVID-19). Edukatif: Jurnal IImu Pendidikan, 2(1), 28-37.

Siedentop, D., Hastie, P. A., \& Mars, H. van der. (2011). Complete Guide to Sport Education (2nd ed.). United States: Human Kinetics.

Sugiyono. (2015). Metode Penelitian Pendidikan (Kuantitatif, Kualitatif dan $R \& D)$. Bandung: Alphabeta.

Sukirno. (2010). Belajar Cepat Menulis Kreatif Berbasis Kuantum Untuk Yang Ingin Cepat Terampil Menulis Kreatif. Yogyakarta: Pustaka Pelajar.

Sutopo. (2012). Teknologi Informasi dan Komunikasi dalam Pendidikan. Yogyakarta: Graha IImu.

Uno, H. (2006). Orientasi Baru Dalam Psikologi Pembelajaran. Jakarta: Bumi Aksara.

Wiarto, G. (2016). Media Pembelajaran dalam Pendidikan Jasmani. Yogyakarta: Laksitas.

Widiyanti, N. L. P. M., Julyasih, N. K. S. M., \& Santiasa, I. M. P. A. (2020). Pelatihan 